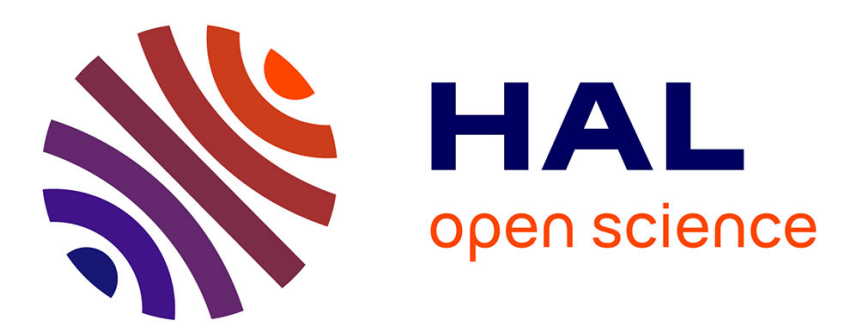

\title{
Fault detection and isolation of PEM fuel cell system based on nonlinear analytical redundancy
}

\author{
A. Aitouche, Q. Yang, B. Ould Bouamama
}

\section{To cite this version:}

A. Aitouche, Q. Yang, B. Ould Bouamama. Fault detection and isolation of PEM fuel cell system based on nonlinear analytical redundancy. European Physical Journal: Applied Physics, 2011, 54 (2), 10.1051/epjap/2011100250 . hal-00699211

\section{HAL Id: hal-00699211 \\ https://hal.science/hal-00699211}

Submitted on 20 May 2012

HAL is a multi-disciplinary open access archive for the deposit and dissemination of scientific research documents, whether they are published or not. The documents may come from teaching and research institutions in France or abroad, or from public or private research centers.
L'archive ouverte pluridisciplinaire HAL, est destinée au dépôt et à la diffusion de documents scientifiques de niveau recherche, publiés ou non, émanant des établissements d'enseignement et de recherche français ou étrangers, des laboratoires publics ou privés. 


\title{
Fault Detection and Isolation of PEM Fuel Cell System based on Nonlinear Analytical Redundancy
}

\section{An application via Parity Space Approach}

\author{
A. Aitouche ${ }^{1 \mathrm{a}}, \mathrm{Q}$. Yang ${ }^{1}$ and B. Ould Bouamama ${ }^{2}$ \\ 1 LAGIS-HEI, 13, rue de Toul, 59046, Lille, France \\ ${ }^{2}$ LAGIS-Polytech-Lille, Rue Paul Langevin, 59655, Villeneuve d'Ascq, France.
}

Received: date / Revised version: date

\begin{abstract}
This paper presents a procedure dealing with the issue of fault detection and isolation (FDI) using nonlinear analytical redundancy (NLAR) technique applied in a proton exchange membrane (PEM) fuel cell system based on its mathematic model. The model is proposed and simplified into a five orders state space representation. The transient phenomena captured in the model include the compressor dynamics, the flow characteristics, mass and energy conservation and manifold fluidic mechanics. Nonlinear analytical residuals are generated based on the elimination of the unknown variables of the system by an extended parity space approach to detect and isolate actuator and sensor faults. Finally, numerical simulation results are given corresponding to a faults signature matrix.
\end{abstract}

\section{Introduction}

Fuel cell system is considered as a significant power source with great potential applications in industry [1]. Two major applications have been widely developed in recent years: stationary and mobility. Fuel cell technology is a favorable candidate for the development of stationary power plant but unfortunately, its full commercial application is not ready due to the high cost and limited durability [2]. In fuel cell mobility applications, two sub-categories are consisted: portable power supply for electronic devices (laptop computers, cellular phones etc.) and transport applications mostly known as fuel cell vehicle (FCV) development [3] - [10]. Comparing of these two sub-categories in mobility applications, fuel cell propulsion system for automobiles is more popular in recent research and development works. As a potential alternative power source, a fuel cell stack needs to be integrated with other components to form a fuel cell system for the power supply function. Consequently, structural coupling of each part in the fuel cell system makes its control and diagnosis problem much difficult, which attracts a large number of researchers focusing on those two intensive domains.

Due to its multi-disciplinary behavior while functioning, it is always a major challenge to fully understand all physical chemical properties from system performance. Therefore, fuel cell system diagnosis plays an important role for its industrial development. On the one hand, diagnostic tools can help distinguish the structure-property-performance

Send offprint requests to: Abdel Aitouche

${ }^{a}$ email: abdel.aitouche@hei.fr relationships between a fuel cell and it components. On the other hand, results obtained from diagnosis also provide benchmark-quality data for fundamental models, which further benefit in prediction, control, and optimization of various transport and electrochemical processes occurring within fuel cells [11]. In recent literatures, fuel cell diagnosis can be classified into two groups: the one using experimental approaches based on knowledge and data and the other with information approaches based on mathematical model. A great part of the fuel cell diagnosis is based on experimental methods, which only consist in cellular and stack level. Among these methods, the Polarization Curve and the Electrochemical Impedance Spectroscopy (EIS) also called AC impedance studied by Yuan et al. [12], [13] and [14] are usually considered as powerful technique tools for characterizing and investigating in-situation of fuel cell [11] in aspect of electro-chemistry. Many other physical/chemical methods for design of test equipment integrated with diagnostic techniques consider current density distribution along the active area in a fuel cell as a very critical parameter [15]. Integration of several well known in situ physical/chemical diagnostic methods including polarization curve, cyclic voltammetry, linear sweep voltammetry, EIS and direct gas mass spectroscopy in open circuit conditions [16] is always used as an effective way to explore the cell degradation mechanisms which usually cause irreversible failure. Besides of certain synthetic experimental diagnostic techniques, several specific parameters such as reactant gas pressure with open current voltage (OCV) discussed by Tian et al. [17] and pressure drop frequency applied by Chen et al. [18] etc. 
are also developed as indicators sensitive to a variety of faults not only for fault detection bus also for fault localization. One of fuel cell diagnosis methods, based on the current interruption (CI) technique, has been proposed by Rubio et al. [19]. Despite of an equivalent circuit model employed, this approach is still more highlighted in physical/chemical experiences. In fault factors analysis, liquid water distribution takes an important role because of its intensive relation with flooding within fuel cells. Therefore, diagnostic test methods which provide insight into the distribution of liquid water in a fuel cell are also interested to be studied [20].

Comparing to experimental approaches, model based fault detection and isolation methods for fuel cell diagnosis are more significant and sophisticated in system level. Due to the portability and compatibility with other industrial processes, model based FDI approaches have great capabilities in adaptive with other auxiliaries to perform a global compartment. In other words, integration with a model based diagnosis system, both fuel cell power plant and fuel cell propulsion transport installation can realize the on board objective. Model based FDI approaches consist in the generic property of the model and its operating conditions. Usually, in a fuel cell power system, each component is sensitive to some specific faults. Hydrogen leakage is one of the potentially dangerous faults which needs to be with great attentions. Ingimundarson et al. [21] presented a model based on mass balances for hydrogen leak detection in PEM fuel cell systems. Unlike the hydrogen leakage as a single fault, fuel cell power plant faults can occur in any parts on any time. A hybrid model based on neural network is proposed by Yang et al. [22] to designe a fuzzy fault diagnosis and accommodation system for fuel cell power plant. Another model based fault identification in fuel cells is presented by Riascos et al. [23] based on Bayesian network. A stochastic approach is shown in [24] by Hernandez et al. to estimate fuel cell operation/failure mode, using the information provided by an individual cell voltage probability density function. Other model based FDI techniques such as parameter estimation based on system identification [25], LPV observer based approach [26] for parametric uncertainty, are not focused in this paper. Besides of the model based diagnostic methods mentioned above, analytical redundancy (AR) is well considered as a valuable tool, which takes an extra significant position, to provide information for FDI. In contrast to physical redundancy which is often used as diagnostic tool in non model FDI approaches, when measurements from parallel sensors are compared to each other, for AR technique, sensory measurements are compared to analytically computed values of respective variable. Such computations use present and/or previous measurements of other variables, and the mathematical plant model describing their nominal relationship to the measured variable. The idea can be extended to the comparison of two analytically generated quantities, obtained from different sets of variables. In either case, the resulting differences, called residuals, are indicative of the presence of faults in the system. By comparing the AR technique with the other model based FDI methods, the causality between variables are well excavated and exploited for the purpose of diagnosis. This characteristic is also a common among various approaches which are used for redundancy generation, e.g. Bond Graph approach [27], structural analysis [28] and etc.

Parity space approach which is also belonging to AR techniques, specially intended to linear models [29]. In recent years, its extension to nonlinear system models are well developed [30]. Applications have been proposed in particular conditions [30], [31]. For fuel cell system, fault detection and isolation via parity space in nonlinear case have been studied in several specific components [32].

In this paper, nonlinear analytical redundancy technique via parity space approach will be applied to the global system of PEM fuel cell in objective of fault detection and isolation. The organization is as follows. In section 2 , the nonlinear state space modeling is presented based on fuel cell physics. Section 3 proposes the procedure to generate nonlinear analytical redundancy (residuals) via parity space approach. Section 4 provides simulation results with residuals analysis and time evolution. Conclusions are presented in section 5 .

\section{Nonlinear State Space Modeling of Fuel Cell System}

\subsection{General Model of Fuel Cell System}

Modeling of a fuel cell system concerns multi-physical domains such as electrochemical, thermodynamic, electric and fluid mechanic principles. In this paper, we focus on the studying of the PEM fuel cell system usually used in vehicular transport applications such as FCV or HEV.

A single PEM fuel cell is a volumetric capacitor including two electrodes named as cathode (ca) and anode (an) which sandwich an electrolyte inside the proton exchange membrane with bipolar plates. The whole combination of the three parts in the fuel cell is generally called as a Membrane Electrode Assemblies (MEA).

The electrolyte has a special property that allows positive ions (protons) to pass through while blocking electrons. Hydrogen gas passes over the anode, and with the help of a catalyst, separates into electrons and hydrogen protons (Fig. 1.).

$$
2 \mathrm{H}_{2} \Rightarrow 4 H^{+}+4 e^{-}
$$

Then the protons flow to the cathode through the electrolyte while the electrons flow through an external circuit, thus creating electricity. At the mean time, the hydrogen protons and electrons combine with oxygen flow through the cathode to produce water.

$$
\mathrm{O}_{2}+4 \mathrm{H}^{+}+4 e^{-} \Rightarrow 2 \mathrm{H}_{2} \mathrm{O}
$$

The overall reaction of the fuel cell is therefore:

$$
2 \mathrm{H}_{2}+\mathrm{O}_{2} \Rightarrow 2 \mathrm{H}_{2} \mathrm{O}+\text { heat }
$$




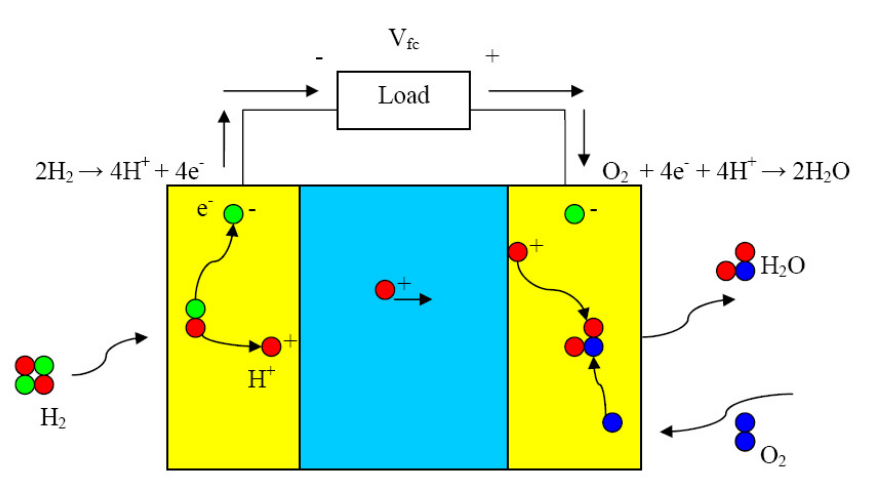

Fig. 1. Fuel cell principles

The voltage produced from one cell is between 0 and 1 volts [33], [41] depending on fuel cell operating conditions and the size of the load connected to the fuel cell. The typical value of one fuel cell voltage is about 0.7 volts. To get higher voltage for industrial applications, multiple cells are stacked in series. The total stack voltage is the number of cells multiplied by the average cell voltage. There are electrical resistances in the fuel cell as other electrical devices. The loss associated with the resistance is dissipated in the form of heat, which means that heat is released from the fuel cell reaction. In this paper, to guarantee the normal function of the fuel cell system, the temperature of operating condition is maintained at $77^{\circ} \mathrm{C}$. The fuel cell system contains several auxiliary components, which has been simplified for control and diagnosis (Fig. 2.).

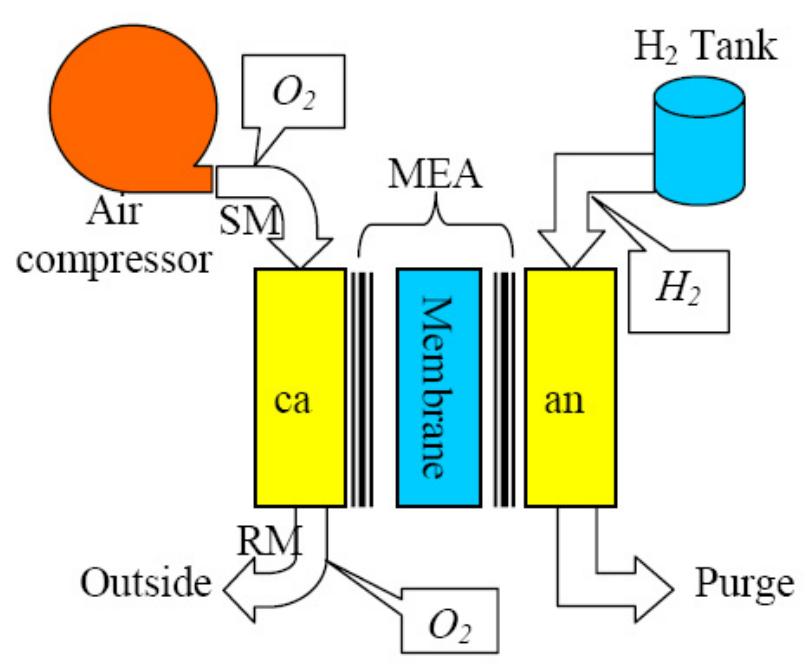

Fig. 2. Scheme of PEM fuel cell system model

- Air compressor: a volumetric air compressor, which is the basic device of air supply sub-system for the fuel cell, functions to increase the air gas pressure in assurance of the continuity of the fuel cell reaction.

- Hydrogen tank: a high pressure or cryogenic hydrogen tank, which is connected to control valve, can improve the reaction rate.

- Supply manifold (SM): a supply manifold volume includes the volume of the pipes between the compressor and the fuel cell stack, which contains the volume of the cooler and the humidifier. It is also one of the components in the air supply sub-system.

- Return manifold (RM): a return manifold represents the pipeline at the fuel cell stack exhaust.

- Fuel cell stack: a fuel cell stack is constructed by a number of fuel cells (usually a few hundred), which becomes the most important component in the fuel cell system and the main power generator converting chemical energy to electrical energy.

The cooperation of each component in appropriate functions ensures the whole system as a power supply device for vehicle.

Model developed specially for control and diagnosis studies have certain properties. In this paper, we use the physical model developed and validated by [34], which includes important characteristics such as dynamics (transient) effects but neglects spatial variation of parameters. Based on this control oriented physical model, we proposed a state space representation in nonlinear for fault detection and isolation.

\subsection{Modeling hypotheses}

In order to realize the objective of fault detection and isolation, several hypothesis need to be proposed for the mathematical modeling procedure:

- Multiple cathode and anode volumes of the multiple identical fuel cells composing the stack are lumped together as a global unit.

- The reactant gas air is assumed by pure oxygen and another reactant gas is pure hydrogen.

- All gases are supposed to satisfy the ideal gas law.

- There is no parasitic reaction considered inside the stack.

- The humidification effect is not considered in both compressor and supply manifold due to the high temperature.

- The stack temperature is uniform including the cathode channel and the anode channel.

- The variation of canals volume is negligible.

- Hydrogen gas is assumed to be completely consumed.

- In the Supply manifold, the gas is supposed to be ideal and works in isothermic condition.

- The temperature of the air leaving the stack is relatively low compared to the air leaving the compressor. Therefore, the changes of air temperature in the return manifold are negligible.

- Reactant gas always behaves like an ideal gas. Secondly, the temperature of the fuel cell stack is perfectly 
by controlled by the cooling system such that its temperature is maintained constant at $350 \mathrm{~K}$ and uniformly over the whole stack. Furthermore, the flow temperature within the cathode flow channel is assumed to be the same as the stack temperature. Thirdly, as mentioned before, outlet flow variables of the cathode are assumed to be equal to the variables inside the cathode flow channel, including gas temperature and pressure. Lastly, the follow channel and cathode backing layer are lumped into one volume, i.e. the spatial variations are ignored.

- In the modeling of the anode flow, hydrogen is supplied to the anode of the fuel cell stack by a pressurized tank. It is assumed that the anode inlet flow rate can be instantaneously adjusted by a valve to maintain the minimum pressure difference between the cathode and the anode. Then we assume that the anode channel flow resistance is small as compared to the cathode flow resistance such that maintaining the pressure difference ensures sufficient flow of hydrogen for the fuel cell reaction. Then other assumptions similar to the cathode flow model are also validated. The temperature of the gas flow is assumed the same as the stack temperature. It is assumed that the condition, namely pressure, temperature of the anode outlet flow is the same as the condition of the gas in the anode flow channel. Additionally, the flow channel and the backing layer of all cells are lumped into one volume.

\subsection{Mathematical Model}

The dynamic behavior of the compressor speed $\omega_{c p}$, which is considered as one of the state variables, can be governed by a lumped rotational parameter model [34] with inertia as follow:

$$
J_{c p} \frac{d \omega_{c p}}{d t}=\tau_{c m}-\tau_{c p}
$$

The torque required to drive the compressor $\tau_{c p}$ is calculated using thermodynamic equations:

$$
\tau_{c p}=\frac{C_{p}}{\omega_{c p}} \frac{T_{a t m}}{\eta_{c p}}\left[\left(\frac{p_{s m}}{p_{a t m}}\right)^{\frac{\gamma-1}{\gamma}}-1\right] W_{c p}
$$

where $p_{s m}$ is the air pressure in the supply manifold, which is the state variable in the dynamic equation (9).

The compressor motor torque $\tau_{c m}$ is calculated using a static motor equation:

$$
\tau_{c m}=\eta_{c m} \frac{k_{t}}{R_{c m}}\left(v_{c m}-k_{v} \omega_{c p}\right)
$$

where the compressor motor input voltage $v_{c m}$ is chosen as one of the input variables of the whole system due to its contribution to different levels of steady-state performance. Not only as a control variable, but also the input voltage is sensitive to additional faulty signal.

For the supply manifold, the inlet mass flow is the compressor outlet mass flow, $W_{c p}$ considered as a constant in this paper, and the outlet mass flow, $W_{\text {sm,out }}$, can be calculated by a linearized form of the sub-critical nozzle flow equation, since the pressure difference between the supply manifold and the cathode is relatively small:

$$
W_{\text {sm,out }}=k_{\text {sm,out }}\left(p_{\text {sm }}-p_{\text {ca }}\right)
$$

We assume that all variables of the flow exiting the cathode are the same as the variables inside the cathode flow channel, therefore, $p_{c a}=p_{c a, \text { out }}$. Since the supply air flow is assumed as the pure oxygen flow $p_{\mathrm{O}_{2}, c a}$, which follows the ideal gas law:

$$
p_{c a, \text { out }}=p_{\mathrm{O}_{2}, \mathrm{ca}}=\frac{m_{\mathrm{O}_{2}, c a} R_{\mathrm{O}_{2}} T_{s t}}{V_{c a}}
$$

where $m_{\mathrm{O}_{2}, c a}$ is oxygen mass in the cathode as the state variable in the dynamic equation (13).

Since the temperature of the air in the supply manifold is high after the compression, it is expected that the air temperature changes inside the manifold. Thus, the supply manifold pressure dynamic equation is derived from the energy conservation and the ideal gas law in isothermic condition:

$$
\frac{d p_{s m}}{d t}=\frac{\gamma R_{a}}{V_{s m}}\left(W_{c p} T_{c p, \text { out }}-W_{\text {sm,out }} T_{s m}\right)
$$

where the air temperature of compressor outlet $T_{c p, o u t}$ is considered as the second input in the system model, which is not sensitive to any fault considered in this paper.

The dynamic equation of the return manifold pressure $p_{r m}$ is modeled by

$$
\frac{d p_{r m}}{d t}=\frac{R_{a} T_{r m}}{V_{r m}}\left(W_{\text {ca,out }}-W_{r m, \text { out }}\right)
$$

where the $W_{\text {ca,out }}$ and $W_{\text {rm,out }}$ are, respectively, the cathode outlet flow rate and the return manifold outlet flow rate.

Since the small pressure difference between the cathode volume and the return manifold and also the return manifold is directly connected to the atmospheric environment, both of the outlet flow equations can also be presented similarly as (7):

$$
\begin{aligned}
& W_{\text {ca }, \text { out }}=k_{\text {ca,out }}\left(p_{\text {ca }, \text { out }}-p_{r m}\right) \\
& W_{r m, \text { out }}=k_{r m, \text { out }}\left(p_{r m}-p_{\text {atm }}\right)
\end{aligned}
$$

where $k_{r m, o u t}$ is the third input which is fixed at a constant in order to be adaptive with the state space structure. Inside the cathode, the mass flow model represents the reactant oxygen flow behavior. The model is developed using the mass conservation principle and thermodynamic and psychometric properties of oxygen. The state equation developed by mass continuity for oxygen balance inside the cathode is as follow: 


$$
\frac{d m_{\mathrm{O}_{2}, \mathrm{ca}}}{d t}=W_{c a, \text { in }}-W_{c a, \text { out }}-W_{\mathrm{O}_{2}, \text { reacted }}
$$

where the inlet mass flow rate of the cathode is the same as the outlet one of the supply manifold because of the direct connection between the parts, $W_{c a, \text { in }}=W_{\text {sm,out }}$ given by (7). And the outlet mass flow rate $W_{c a, \text { out }}$ has been given in (11). The rate of oxygen consumption $W_{O_{2}}$,reacted can be calculated by electro-chemistry principles:

$$
W_{O_{2}, \text { reacted }}=M_{O_{2}} \times \frac{n I_{s t}}{4 F}
$$

where the stack current $I_{s t}$ is the last input which could be controlled and also be added with a faulty signal.

We assume that the anode supply manifold is small and its volume is lumped together with the anode volume, i.e. they have the same pressure, and the anode inlet pressure is used in a proportional controller which is in the form as:

$$
W_{a n, i n}=K_{1}\left(K_{2} p_{s m}-p_{a n}\right)
$$

Similar to the oxygen mass flow state equation, the hydrogen mass flow state equation is also modeled by the continuity of mass flow for hydrogen balance inside the anode:

$$
\frac{d m_{H_{2}, a n}}{d t}=W_{a n, i n}-W_{a n, o u t}-W_{H_{2}, \text { reacted }}
$$

where $m_{H_{2}, a n}$ is the hydrogen mass in the anode, $W_{a n, i n}$ is the anode inlet flow rate given in (15). Under the assumption of the complete consumption of hydrogen in the electro-chemical reaction, the anode outlet mass flow $W_{\text {an,out }}$ is considered as null in this manuscript. Same as reacted oxygen flow, the rate of hydrogen consumed in the

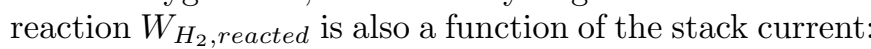

$$
W_{H_{2}, \text { reacted }}=M_{H_{2}} \times \frac{n I_{s t}}{2 F}
$$

All parameters and variables not mentioned in the descriptions can be found in the nomenclature (Tab. 2).

\subsection{Nonlinear State Space Representation}

Based on the physical model under several assumptions, a nonlinear state space representation with five state variables mentioned in the physical model in section 2.3 can be deduced in the following procedure.

The general nonlinear state space representation with the order of $n$ for dynamical system can be written in the following structural form:

$$
\left\{\begin{array}{l}
\dot{x}=f(x)+g(x) u \\
y=h(x)
\end{array}\right.
$$

where $x \in \Re^{n}$ is the state vector, $u \in \Re^{p}$ is the vector of control inputs, $y \in \Re^{m}$ is the output vector. All variables are functions of time $t$. While $f$ is the state function vector, $g$ is the input function matrix and $h$ is the output function vector. All vectors are in appropriate dimensions. In this paper, since that the water vapor mass in the cathode always predicts excessive water flow from anode to cathode which results in fully humidified cathode gas under all nominal conditions. Additionally, the effects of liquid condensation, also known as flooding, are not included in the model neither of the water across the membrane. Hence, we define the state vector with $n=5$ states $x=\left[\omega_{c p}, p_{s m}, p_{r m}, m_{O_{2}, c a}, m_{H_{2}, a n}\right]^{T}=\left[x_{1}, x_{2}, x_{3}, x_{4}, x_{5}\right]^{T}$. Among those state variables, the first three can be measured by installation of certain appropriate sensors such as velocity sensor for compressor rotational speed and pressure sensor for supply manifold and return manifold pressures. Therefore, in our case, $h(x)=C x$.

The state variables are selected based on energy variables. Indeed the rotational speed of the compressor velocity is associated with the kinetic energy, the inlet and return pressure in the manifold are associated with the stored volume. Finally the mass of oxygen and hydrogen in anode and cathode concerns the stored hydraulic energy. The input variables are naturally associated with sources of energy. In our cases are considered as input measured variables while they will be used for diagnosis using Analytical redundancy relation (which is an expression where all variables including inputs and measured outputs). They are : compressor input voltage, output temperature of the air (measured), retour manifold and current of the stack, supply return manifold orifice considered as extra control variable provided by the pressure return manifold controller. Note that the output temperature from a control point of view cannot be considered as an control variable (it's not a source of energy) but for diagnosis system design, this known variable is used for ARR generation. The stack current is generally considered and a disturbance or as an external input imposed by the load. In our case while it is measured, it is selected as an input known variable.

The output vector with $m=3$ outputs is $y=\left[y_{1}, y_{2}, y_{3}\right]^{T}$. The input vector with $p=4$ inputs defined in section 2.3 is $u=\left[v_{c m}, T_{c p, \text { out }}, k_{r m, \text { out }}, I_{s t}\right]^{T}=\left[u_{1}, u_{2}, u_{3}, u_{4}\right]^{T}$. The input function matrix $g$ and the output matrix $C$ are given as follow:

$g(x)=\left[\begin{array}{cccc}g_{1} & 0 & 0 & 0 \\ 0 & g_{2} & 0 & 0 \\ 0 & 0 & g_{3} & 0 \\ 0 & 0 & 0 & g_{4} \\ 0 & 0 & 0 & g_{5}\end{array}\right], C=\left[\begin{array}{lllll}1 & 0 & 0 & 0 & 0 \\ 0 & 1 & 0 & 0 & 0 \\ 0 & 0 & 1 & 0 & 0\end{array}\right]$

where details of the four coefficients $g_{i}(i=1,2,3,4,5)$ can be found in appendix. Different dynamic equations characterizing the fuel cell system can derive the nonlinear state function vector: $f(x)=\left[f_{1}, f_{2}, f_{3}, f_{4}, f_{5}\right]^{T}$, where $f_{j}$ $(j=1,2,3,4,5)$ are given in appendix. 


\section{Generation of Nonlinear Analytical Redundancy via Parity Space Approach}

\subsection{Nonlinear Analytical Redundancy}

Analytical redundancy (AR) is a model-based technique that derives the maximum number of independent tests from the state space representation of the system. These AR tests monitor the consistency of measurements in sensor data with control/diagnosis oriented system model and past control inputs. Through the consistency monitoring between those known variables, the tests can determine whether the system is performing nominally (no fault occurring), or is deviating from the desired plan and presumably under fault conditions. Observability assurance is the prerequisite to provide the capability of AR generation. It is necessary to be observable for the system, but not sufficient. Only the system over-constrained with configuration of sensors are able to generate AR for FDI procedure. Intuition and elegance are the two core notions of analytical redundancy. Firstly, AR exploits the basic concept of observability, namely, that the key information which can be learned about the model-based behavior of a system can be inferred from the observation space. Then the processing of that information in such a way is to generate a formally complete set of residual tests which are guaranteed both to be linearly independent and to test for all detectable deviations from the system model. Thus, every residual contains at least some information not contained in other residuals, and every observable deviation from the system model is accounted for by at least one of the AR residuals. More descriptions and comparisons with other model based FDI approaches can be found in [35] and [36]. The FDI procedure based on AR residuals generation is classified into two groups: linear case and nonlinear case. For the first one, many useful properties of linear systems or linearized systems have been exploited over years to make them tractable. Applications of linear AR for fault detection and accommodation have been well developed by [37] based on parity space, [38] based on unknown input observer. However, for the second one, direct derivation of $\mathrm{AR}$ in nonlinear systems, which do not obey the superposition principle and can exhibit behaviors such as finite escape times, multiple equilibria or chaos, is quite difficult to deal with. As a result of these nonlinear properties, even if the observability is made much more difficult. In this paper, we use the nonlinear analytical redundancy (NLAR) directly generated by parity space approach to detect and isolate faults in PEM fuel cell system.

From the generic point of view, linear system could be regarded as a specific type of nonlinear system. In other words, the set of all linear systems is contained in the set of all nonlinear systems in generalized sense. Therefore, the NLAR approach can be considered as an extension of the linear AR technique. Obviously, the computation of the nonlinear residual tests is more complex and difficult. Thanks to the parity space approach extended by [30] into nonlinear case, the generation and evaluation of all potential residuals are become reality. More detail information with numerical calculation has been given in the procedure instead of structural form. Nonlinear systems theory including local observability and smoothness etc. is applied to the development of this procedure.

Based on the general nonlinear state space representation (18), the triangular nonlinear observability $O_{\Delta}$ is expressed as follow:

$$
\begin{aligned}
& O_{\Delta}= \\
& {\left[\begin{array}{c}
h(x) \\
L_{f} h+L_{g} h u \\
L_{f f} h+L_{g f} h u+L_{f g} h u+L_{g g} h u^{2} \\
\left\{\begin{array}{c}
L_{f f f} h+\left(L_{g f f} h+L_{f g f} h+L_{f f g} h\right) u+ \\
\left(L_{g g f} h+L_{g f g} h+L_{f g g} h+L_{g g g} h\right) u^{2}+ \\
\left(2 L_{g f} h+L_{f g} h\right) \dot{u}+3 L_{g g} h u \dot{u}+L_{g} h \ddot{u}
\end{array}\right\} \\
\ldots
\end{array}\right]}
\end{aligned}
$$

where $L_{k} h=\sum_{i=1}^{n} \frac{\partial h(x)}{\partial x} k_{i}(x)$ is the Lie derivative of scalar function $h$ in the direction of vector function $k$. The Lie derivative expression can be written as $L_{i}\left(L_{j}\left(L_{k} h\right)\right)=$ $L_{i j k} h$. Similar as in linear case, the parity matrix $\Omega$ is deduced via the following expression:

$$
\Omega \times O_{\Delta D D}=[0]
$$

Incorporation of input-output information, the nonlinear dynamically derived observability $O_{\triangle D D}$ reformulated by the observability in terms of multiple control inputs $u_{i}$, and sensor readings $y_{j}$ is needed to complete the AR parity equation. In our case, since $h(x)=C x$, we can write the $O_{\triangle D D}$ as follows:

$$
\begin{aligned}
& O_{\Delta D D}= \\
& {\left[\begin{array}{c}
y-0 \\
\dot{y}-0 \\
\ddot{y}-\sum \dot{u} L_{g} \\
\frac{d^{3} y}{d t^{3}}-\left(\begin{array}{c}
\sum \ddot{u}_{i} L_{g_{i}}+\sum \dot{u}_{i} L_{\dot{x} g_{i}}+\sum \dot{u}_{i} L_{g_{i} f} \\
+\sum \dot{u}_{i} L_{f g_{i}}+\sum u_{i} \sum \dot{u}_{j} L_{g_{i} g_{j}} \\
+\sum \dot{u}_{i} \sum u_{j} L_{g_{i} g_{j}}
\end{array}\right) \\
\ldots
\end{array}\right]}
\end{aligned}
$$

where all of the Lie derivatives used here are with respect to $C x$, thus $L_{g}=L_{g}(C x)=g C$. Nonlinear residuals vector $R=\left[R_{i}\right]^{T}(i=1,2,3 \ldots)$ are obtained by multiplying the parity matrix $\Omega$ by right with the nonlinear dynamically derived observability vector $O_{\triangle D D}$ by left:

$$
R=\Omega \times O_{\Delta D D}
$$

As the rank of the nonlinear observability sub-matrices are always greater than or equal to the ranks of the linear sub-matrices $\left(r_{j}(\right.$ nonlin $)>=r_{j}($ lin $\left.)\right)$, nonlinear analytical redundancy is guaranteed to generate at least as many independent test residuals as linear AR and will possibly generate more. Here we remain the full NLAR generation algorithm as below:

- Determine the triangular nonlinear observability $O_{\Delta}$ and its left null $\Omega$ named as the matrix in parity space after checking the observability of the system. 
- Determine the nonlinear dynamically derived observability $O_{\triangle D D}$.

- Find the rank $r_{j}$ of each observability sub-matrix in the observability matrix. Keep $r_{j}+1$ rows in each subvector.

- Calculate nonlinear residuals by using the NLAR equation: $R=\Omega \times O_{\Delta D D}$.

- Use the equation (23) to determine how many independent residuals there are and delete the redundant residuals.

$$
N=\sum_{i=1}^{m} r_{i}+(m-n)
$$

After the detailed description of the NLAR method based on parity space approach, in the next section, we will apply the technique to the nonlinear state model of the fuel cell system in section 2.4 to generate NLAR residuals.

\subsection{Nonlinear Residuals Generation}

None of any fault is considered in modeling of the fuel cell system. Therefore, the system in nominal state of performance is called as a fault free system. It is necessary to define such a system without any fault as a reference for the FDI procedure. In other words, the system with no fault is in an original mode with respect to other modes in which faulty signals appear to change the equations corresponding to the original model. Therefore, the system without fault or with different faults is regarded as in different mode. In FDI theory, faulty signals are generally classified into three groups: actuator faults, sensor faults and system faults. In our case, four faults within two groups are defined respectively under modeling hypothesis in section 2.4.

- Class 1 of two actuator faults: fault $F_{1}$ (input voltage drop of compressor motor $\Delta v_{c m}$ ) and fault $F_{2}$ (over current of fuel cell stack $\Delta I_{s t}$ ).

- Class 2 of two sensor faults: fault $F_{3}$ (pressure drop in supply manifold $\Delta p_{s m}$ ) and fault $F_{4}$ (pressure increase in return manifold $\left.\Delta p_{r m}\right)$.

In practice, the FDI is not used alone but it is integrated in closed loop as un example the (Fig. 3) represents a fault tolerant scheme [42].

In this paper, we assume that no system faults are considered. Besides, only one fault scenario occurs in each time, which means, the case of multiple faults appearing at one time is not concerned. Since all unknown variables are eliminated through parity space approach, all of NLARs only contain inputs and outputs of the system model as known variables. Therefore, those four faults can be represented by input and output symbols. Precisely, faults $F_{1}$ and $F_{2}$ are represented, respectively, by inputs $u_{1}$ and $u_{4}$ in residual equations. Similarly, faults $F_{3}$ and $F_{4}$ are represented, respectively, by outputs $y_{2}$ and $y_{3}$. From the point of view for system implementation, a residuals generator is constructed with all NLAR residual equations

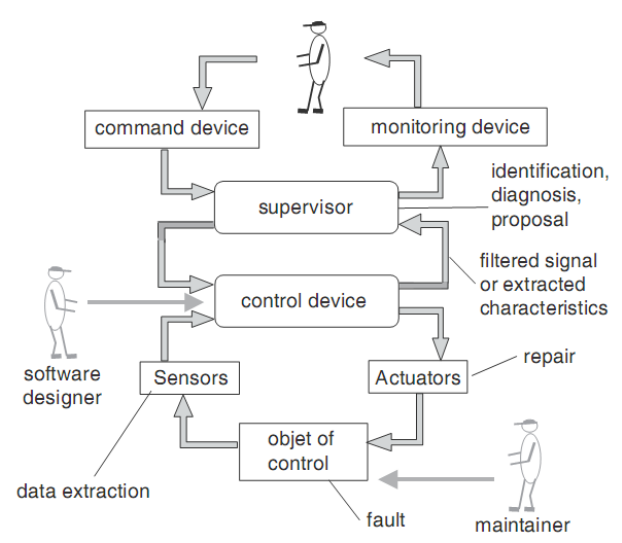

Fig. 3. Structure of a fault-tolerant system

produced by the algorithm remained in section 3.1. By using the redundant test equation (23), we obtain seven independent residuals out of eleven. However, in our case, with four residuals which are sensitive to different combination of faults from each other, it is sufficient to realize the objective of fault detection and isolation for the whole system. These four residuals are presented as follows:

$$
\begin{aligned}
& R_{1}=\frac{k_{t} k_{v} \eta_{c m} y_{1}}{J_{c p} R_{c m}}+\frac{C_{p} T_{a t m} W_{c p}}{J_{c p} \eta_{c p} y_{1}}\left[\left(\frac{y_{2}}{p_{a t m}}\right)^{\frac{\gamma-1}{\gamma}}-1\right] \\
& -\frac{k_{t} \eta_{c m} u_{1}}{J_{c p} R_{c m}}+\dot{y}_{1} \\
& R_{2}=\dot{y}_{2}+\frac{\gamma R_{a} k_{s m, o u t} T_{s m}}{V_{s m} R_{a} T_{s m} k_{s m, o u t}} \times \\
& \left.\quad-\frac{\gamma R_{a} W_{c p}}{V_{s m}} u_{2}-\frac{\gamma R_{c a, o u t} V_{s m}}{k_{s m}} \times \frac{V_{r m}}{R_{a} T_{r m}} \dot{y}_{3}\right) \\
& \quad\left(k_{c a, o u t} y_{3}+\left(y_{3}-p_{a t m}\right) u_{3}\right)
\end{aligned}
$$

$$
\begin{aligned}
& R_{3}=\ddot{y}_{2}-\frac{\gamma R_{a} W_{c p}}{V_{s m}} \dot{u}_{2}+\frac{\gamma R_{a} k_{s m, o u t} T_{s m}}{V_{s m}^{2} V_{c a}^{2} F} \times \\
& \left\{\begin{array}{l}
\left(\begin{array}{l}
\gamma R_{a} k_{s m, o u t} T_{s m} V_{c a} F R_{O_{2}} T_{s t}+ \\
R_{O_{2}}^{2} T_{s t}^{2} V_{s m} F k_{s m, o u t}+ \\
R_{O_{2}}^{2} T_{s t}^{2} V_{s m} F k_{c a, \text { out }}
\end{array}\right) Y \\
-k_{c a, \text { out }} V_{c a} F\left(\gamma R_{a} T_{s m} V_{c a}+R_{O_{2}} T_{s t} V_{s m}\right) y_{2} \\
-k_{s m, o u t} T_{s t} V_{c a} F R_{O_{2}} V_{s m} y_{3} \\
+\gamma R_{a} W_{c p} V_{c a}^{2} F u_{2} \\
+\frac{R_{O_{2}} T_{s t} M_{O_{2}} n V_{s m} V_{c a} u_{4}}{4}
\end{array}\right\}
\end{aligned}
$$




$$
\begin{aligned}
& R_{4}=\ddot{y}_{3}+\frac{R_{a} T_{r m}}{V_{r m}}\left(y_{3}-p_{a t m}\right) \dot{u}_{3}+\frac{R_{a} T_{r m}}{V_{r m}^{2} V_{c a}^{2} F} \times \\
& \left\{\begin{array}{l}
R_{a} T_{r m} k_{c a, \text { out }} R_{O_{2}} T_{s t} F\left(R_{a} T_{r m} k_{c a, \text { out }} V_{c a}\right. \\
+R_{O_{2}} T_{s t} V_{r m} k_{s m, \text { out }}+k_{c a, \text { out }} R_{O_{2}} T_{s t} V_{r m} \\
\left.+V_{r m} V_{c a} u_{3}\right) Y \\
-\left(R_{a} T_{r m} k_{c a, \text { out }}^{2} V_{c a}^{2} F+k_{c a, \text { out }}^{2} R_{O_{2}} T_{s t} V_{r m} F V_{c a}\right. \\
\left.+2 R_{a} T_{r m} k_{c a, \text { out }} V_{c a}^{2} F u_{3}+R_{a} T_{r m} V_{c a}^{2} F u_{3}^{2}\right) y_{3} \\
-k_{c a, \text { out }} R_{O_{2}} T_{s t} V_{r m} F k_{s m, \text { out }} y_{2} \\
+R_{a} T_{r m} k_{c a, \text { out }} V_{c a}^{2} F p_{a t m} u_{3} \\
+V_{c a}^{2} R_{a} T_{r m} F p_{a t m} u_{3}^{2} \\
+\frac{1}{4} R_{a} T_{r m} k_{c a, \text { out }} R_{O_{2}} T_{s t} V_{r m} V_{c a} M_{O_{2}} n u_{4}
\end{array}\right.
\end{aligned}
$$$$
\text { with }: Y=\frac{V c a}{R_{O_{2}} T_{s t} k_{c a, \text { out }}}\left(\begin{array}{l}
k_{\text {ca,out }} y_{3} \\
+\left(y_{3}-p_{a t m}\right) u_{3} \\
+\frac{V_{r m}}{R_{a} T_{r m}} \dot{y}_{3}
\end{array}\right)
$$

Based on the structural form of those residuals in function of faults, we regroup them into a table (Tab. 1) named as faults signature matrix (FSM). This table is full of Boolean values. When the value 1 appears, it means that the residual $R_{i}$ (in column) is sensitive to the fault $F_{j}$ (in row), otherwise, the value 0 takes the place. Each combination of binary values corresponding to residuals with respect to a unique fault can be regarded as a signature of this fault. With this kind of signatures, we can potentially distinguish all faults from each other as long as no identity signatures of different faults exist. In one word, we are able to examine the detectability $(D b)$ and isolability (Ib) for the whole system based on the FSM. In our case, the results show that all actuator and sensor faults defined before are not only detectable but also isolable since all $\mathrm{Db}$ and $\mathrm{Ib}$ values are equal to 1 .

Table 1. Faults Signature Matrix

\begin{tabular}{ccccccc}
\hline & $R_{1}$ & $R_{2}$ & $R_{3}$ & $R_{4}$ & $D b$ & $I b$ \\
\hline$F_{1}$ & 1 & 0 & 0 & 0 & 1 & 1 \\
\hline$F_{2}$ & 0 & 0 & 1 & 1 & 1 & 1 \\
\hline$F_{3}$ & 1 & 1 & 1 & 1 & 1 & 1 \\
\hline$F_{4}$ & 0 & 1 & 1 & 1 & 1 & 1 \\
\hline
\end{tabular}

\section{Simulation Results}

The NLAR residuals generator is modeled by Simulink in Matlab to produce the four residuals $\left(R_{1}\right.$ to $\left.R_{4}\right)$ chosen as faults indicators in section 3.2. Since the system with different faults can be classified into different modes, five modes of the system are simulated, including the mode of no fault. For the simulation, the nominal operating conditions have been decided as below:
- The input voltage of the compressor motor $v_{c m}=$ $250 \mathrm{~V}$.

- The outlet temperature of the compressor $T_{c p, o u t}=$ $500 K$.

- The return manifold outlet orifice constant $k_{r m, o u t}=$ $0.3629 \times 10^{-5} \mathrm{~kg} / \mathrm{s} / \mathrm{Pa}$.

- The stack current $I_{s t}=150 \mathrm{~A}$.

Under those conditions, we simulate each system mode during the time of $T=30 \mathrm{~s}$ for residuals evolution. It is also noted that all faulty signals are additive and visible. They are assumed to appear during the time from $t=10 \mathrm{~s}$ to $t=20 \mathrm{~s}$, which is called as a failure time. In corresponding to the FSM (Tab.1), all simulation results are provided as below.

First of all, the mode without fault called as fault free system (Fig. 4) shows that all four residuals are convergent rapidly to zero, which is consistent with the anticipation in theory. Since simulation trials have been given in the absence of faults, thresholds can be set on the basis of the maximum values of the residuals. Two symmetric values with respect to zero (positive and negative) are chosen as thresholds. With those thresholds fixed by simulation, a maximum of false alarms and a maximum of non detections could be avoided. In our case, the same residual in different faulty mode will have different thresholds which are adaptive to the variety of situations. For the fault of input voltage drop of compressor motor $F_{1}$, we added a negative value $\Delta v_{c m}=-200 \mathrm{~V}$ to the input voltage as a modeled faulty signal during the failure time. As a result, only the residual $R_{1}$ is different to zero during the time of fault existence (Fig. 5). The thresholds are \pm 5 for $R_{1}$ in this case. For the fault of over current of fuel cell stack $F_{2}$, we added a positive value $\Delta I_{s t}=150 A$ to the stack current as a modeled faulty signal during the failure time. It is noted that $R_{3}$ and $R_{4}$ sensitive to $F_{2}$ have changed from zero between $t=10 \mathrm{~s}$ and $t=20 \mathrm{~s}$ (Fig. 6). The thresholds for $R_{3}$ are \pm 8 while for $R_{4}$ are \pm 10 . For the fault of pressure drop in supply manifold $F_{3}$, a negative value $\Delta p_{s m}=-1.6 \times 10^{5} p a$ is added to the measurement of supply manifold pressure. With the modeled faulty signal during the failure time, all four residuals are not equal to zero when faults occurring. (Fig. 7). The thresholds are, respectively, \pm 0.3 for $R_{1}, \pm 1$ for $R_{2}, \pm 2$ for $R_{3}$ and \pm 1 for $R_{4}$. This results shows that all four residuals are sensitive to the fault $F_{3}$. For the fault of pressure increase in return manifold $F_{4}$, a positive value $\Delta p_{r m}=1.01 \times 10^{5} \mathrm{pa}$ is added to the measurement of return manifold pressure. With the modeled faulty signal during the failure time, these four residuals except $R_{1}$ differed from zero during the time of faults existence (Fig. 8). Similarly, the thresholds are, respectively, \pm 1 for $R_{2}, \pm 0.5$ for $R_{3}$ and \pm 0.5 for $R_{4}$. The last three residuals are sensitive to the fault $F_{4}$ corresponding to the FSM. From these four figures, combinations of all residual values passing over their thresholds could be considered as alarms indicating to faulty signals. However, due to the effectiveness of initialization, it is unavoidable of false alarms appearing during a small time interval at beginnings of the simulation. Hence, only the alarms after the fifth second are validated. 

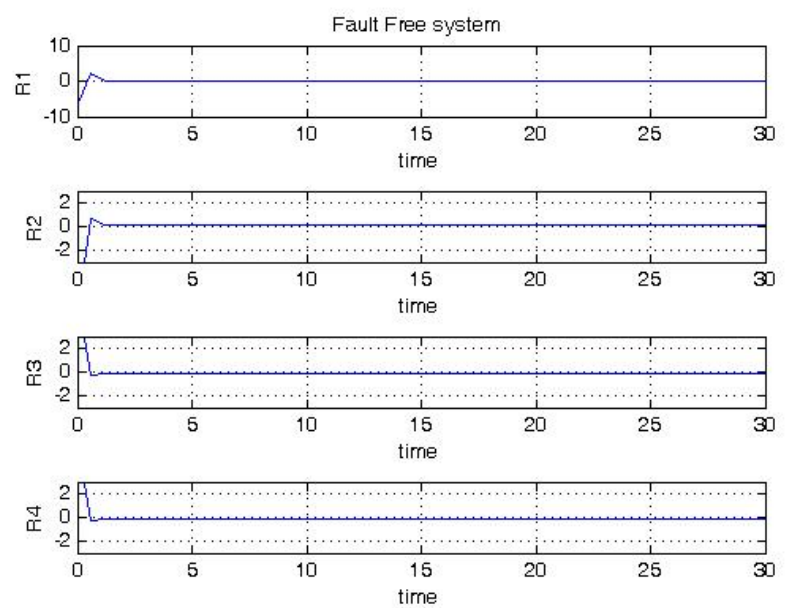

Fig. 4. Residuals evolution of fault free system
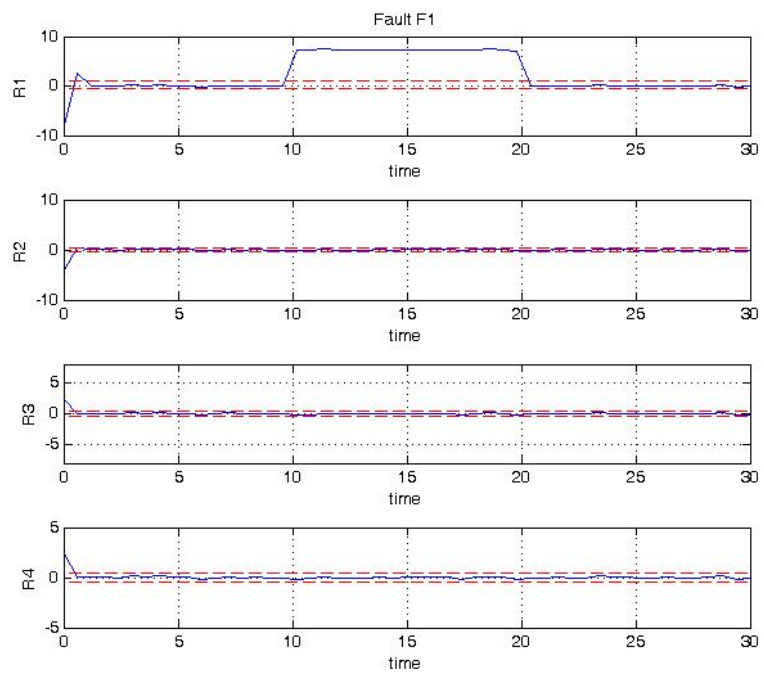

Fig. 5. Residuals evolution of the system with fault $F_{1}$
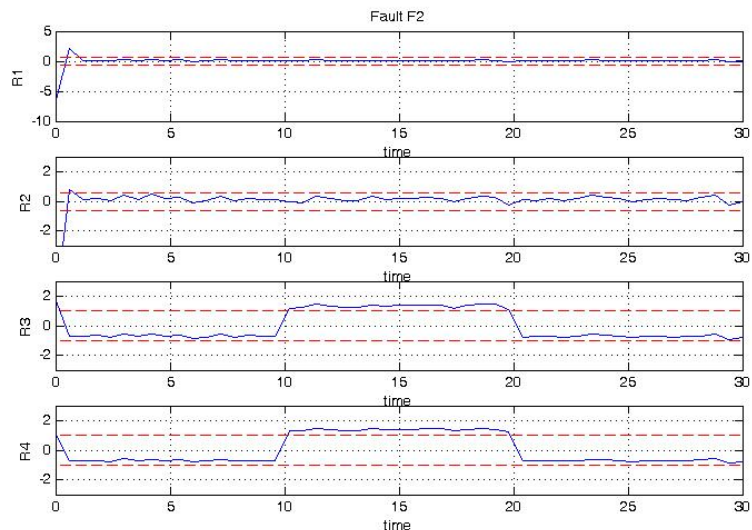

Fig. 6. Residuals evolution of the system with fault $F_{2}$
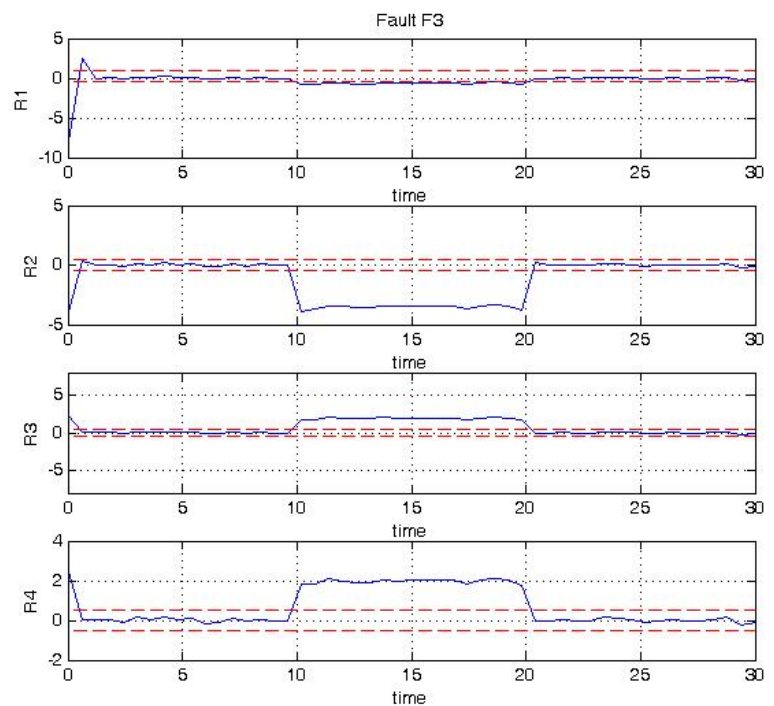

Fig. 7. Residuals evolution of the system with fault $F_{3}$
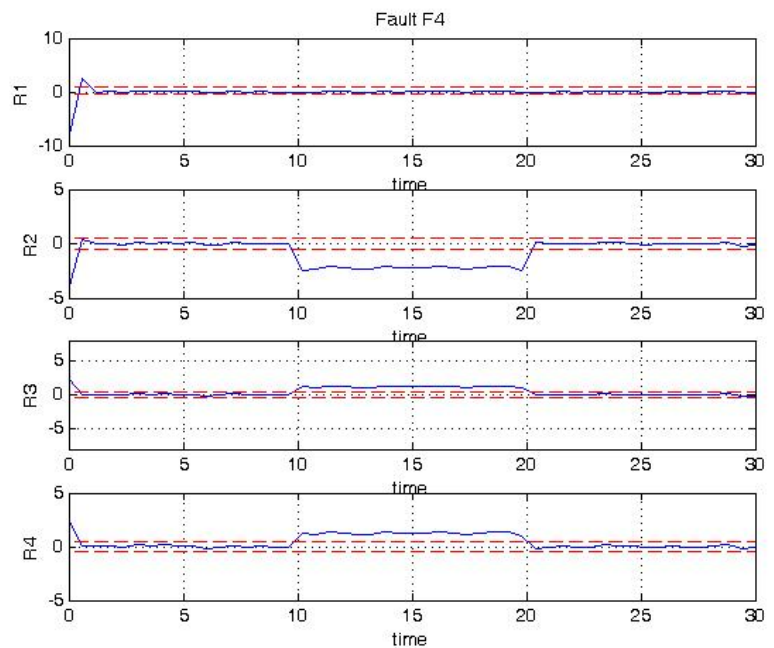

Fig. 8. Residuals evolution of the system with fault $F_{4}$

\section{Conclusion}

An application of fault detection and isolation technique based on nonlinear analytical redundancy has been realized in PEM fuel cell system. Without requiring linearizations as in [29], the procedure of residuals generation via parity space approach extended into nonlinear case is applied directly in the global system of fuel cell based on the nonlinear state model. This is a great progress with respect to the previous work in [32], which has been done only in a subsystem. The extension both from linear to nonlinear and from subsystem to global system demonstrates the power of the analytical redundancy technique in FDI community. Even if that the extra highly nonlinearities of the system will cause tremendous obstacles to 
seize useful information (redundancy) for the purpose of fault detection and isolation, the improved parity space approach can still find potential residuals to complete the information of redundancy group. Faulty signals in this paper are classified into two groups: actuator faults and sensor faults. Through the simulation results, it is shown that all four faults defined in specifications are not only detected but also isolated by the combination of four nonlinear residuals out of seven independent ones. Despite of the noisy disturbance, the correspondence between faults signature matrix and time evolution of residuals is well confirmed.

The presence of the derivatives of both inputs and outputs will amplify the effect of noises which will also mislead residuals in performance of the faults indicators. Therefore, it is important to add thresholds which function as window filters for false alarm signals. However, a controllable signal filter will be more systematic and more appropriate as a solution of this problem. A particular operating condition for residuals generation in this paper is short of generic usefulness. As a consequence, the portability of the residuals generator is limited. Besides, system faults usually caused by parameter variations inside of the fuel cell are not considered, neither of the multiple faults case, which will increase the difficulties of isolation. The sensitivity of residuals with respect to faults, which has been well developed in relative level [39], has also a valuable potentiality in the future. The fault position and the system complexity will affect the residual sensitivity, since coefficients of fault variables in the model have great influence at properties of residuals. It is certain that different structures of system and various positions of faults will lead to uncertainties of residual sensitivity. Finally, as another continuous work, the sensor placement in system level of fuel cell installation will be taken into account for fault diagnosis.

\section{Appendix}

All coefficients in input matrix $g$ are presented as follows:

$$
\begin{aligned}
g_{1} & =\frac{\eta_{c m} k_{t}}{J_{c p} R_{c m}} \\
g_{2} & =\frac{\gamma R_{a} W_{c p}}{V_{s m}} \\
g_{3} & =-\frac{R_{a} T_{r m}}{V_{r m}}\left(x_{3}-p_{a t m}\right) \\
g_{4} & =-\frac{M_{O_{2}} n}{4 F} \\
g_{5} & =\frac{M_{H_{2}} n}{2 F}
\end{aligned}
$$
follows:

All elements of the state function vector $f$ is given as

$$
f_{1}=\frac{-1}{J_{c p}}\left\{\frac{\eta_{c m} k_{t} k_{v} x_{1}}{R_{c m}}+\frac{C_{p} T_{a t m} W_{c p}}{\eta_{c p} x_{1}}\left[\left(\frac{x_{2}}{p_{a t m}}\right)^{\frac{\gamma-1}{\gamma}}-1\right]\right\}
$$

$$
\begin{aligned}
& f_{2}=-\frac{\gamma R_{a} k_{\text {sm }, \text { out }} T_{s m}}{V_{\text {sm }}}\left(x_{2}-\frac{R_{O_{2}} T_{s t}}{V_{c a}} x_{4}\right) \\
& f_{3}=\frac{R_{a} T_{r m} k_{c a, \text { out }}}{V_{r m}}\left(\frac{R_{O_{2}} T_{s t}}{V_{c a}} x_{4}-x_{3}\right) \\
& f_{4}=k_{\text {sm }, \text { out }} x_{2}+k_{\text {ca }, \text { out }} x_{3}-\frac{\left(k_{\text {sm }, \text { out }}+k_{\text {ca }, \text { out }}\right) R_{O_{2}} T_{s t}}{V_{c a}} x_{4} \\
& f_{5}=K_{1}\left(K_{2} x_{2}-\frac{R_{H_{2}} T_{s t}}{V_{a n}} x_{5}\right)
\end{aligned}
$$

All parameters are given in the table of nomenclature (Tab.2) with international standard units of each variable.

\section{References}

[1] M.W. Ellis, M.R. Von Spakovsky and D.J. Nelson, Proceedings of the IEEE vol.89, No.12, (2001) pp.1808-1818.

[2] G. Cacciola, V. Antonucci and S. Freni, Journal of Power Sources vol.100, (2001) pp.67-79.

[3] A. Emadi and S.S. Williamson, Proceedings of the Power Engineering Society General Meeting vol.2, (2004) pp.16401645 .

[4] C. Nitsche, S. Schroedl and W. Weiss, Proceedings of the Intelligent Vehicles Symposium, IEEE, (2004) pp.127-132.

[5] E. Dominguez, J.I. Leon, C. Montero, D. Marcos, M. Rodriguez, C. Bordons, M.A. Ridao, E. Fernandez, E. Lopez and F. Rosa, Proceedings of the Industrial Electronics, IECON '09, 35th Annual Conference of IEEE, (2009) pp.3828-3833.

[6] D.D. Boettner, G.Paganelli, Y.G. Guezennec, G. Rizzoni and M.J. Moran, Transactions of the ASME, Journal of Energy Resources Technology vol.124, (2002) pp.20-27.

[7] C.C. Chan, Proceedings of the IEEE vol.95, No.4, (2007) pp.704-718.

[8] C.C. Chan, Y.S. Wong, A. Bouscayrol and K.Y. Chen, Proceedings of the IEEE vol.97, No.4, (2009) pp.603-607.

[9] C.C. Chan, A. Bouscayrol and K.Y. Chen, IEEE Transactions on vehicular technology vol.59, No.2, (2010) pp.589598.

[10] D. Hissel, D. Candusso and F. Harel, IEEE Transactions on vehicular technology vol.56, No.5, (2007) pp.2414-2420.

[11] J.F. Wu, X.Z. Yuan, H.J. Wang, M. Blanco, J.J. Martin and J.J. Zhang, International Journal of Hydrogen Energy vol.33, (2008) pp.1735-1746.

[12] X.Z. Yuan, H.J. Wang, J.C. Sun and J.J. Zhang, International Journal of Hydrogen Energy vol.32, (2007) pp.43654380 .

[13] X.Z. Yuan, J.C. Sun, M. Blanco, H.J. Wang, J.J. Zhang and D.P. Wilkinson, Journal of Power Sources vol.161, (2006) pp.920-928.

[14] X.Z. Yuan, H.J. Wang, J.C. Sun and J.J. Zhang, Journal of Power Sources vol.161, (2006) pp.929-937.

[15] J.F. Wu, X.Z. Yuan, H.J. Wang, M. Blanco, J.J. Martin and J.J. Zhang, International Journal of Hydrogen Energy vol.33, (2008) pp.1747-1757.

[16] J.F. Wu, X.Z. Yuan, J.J. Martin, H.J. Wang, D.J. Yang, J.L. Qiao and J.X. Ma, Journal of Power Sources vol.195, (2010) pp.1171-1176.

[17] G.Y. Tian, S. Wasterlain, I. Endichi, D. Candusso, F. Harel, X. Francois, M.C. Pera, D. Hissel, J.M. Kauffman, Journal of Power Sources vol.182, (2008) pp.449-461. 
Table 2. Nomenclature

\begin{tabular}{|c|c|c|}
\hline Symbol & Variable description & Value \\
\hline$J_{c p}$ & $\begin{array}{l}\text { compressor and } \\
\text { motor inertia }\end{array}$ & $5 \times 10^{-5} \mathrm{~kg} \cdot \mathrm{m}^{2}$ \\
\hline$\eta_{c m}$ & $\begin{array}{l}\text { compressor mo- } \\
\text { tor mechanical } \\
\text { efficiency }\end{array}$ & $98 \%$ \\
\hline$k_{t}$ & $\begin{array}{l}\text { compressor motor } \\
\text { constant }\end{array}$ & 0.0153 N.m/A \\
\hline$R_{c m}$ & $\begin{array}{l}\text { compressor motor } \\
\text { resistance }\end{array}$ & $0.82 \Omega$ \\
\hline$k_{v}$ & $\begin{array}{l}\text { compressor motor } \\
\text { constant }\end{array}$ & $0.0153 \mathrm{~V} /(\mathrm{rad} / \mathrm{s})$ \\
\hline$C_{p}$ & $\begin{array}{l}\text { specific heat capac- } \\
\text { ity of air }\end{array}$ & $1004 \mathrm{~J} /(\mathrm{mol} . \mathrm{K})$ \\
\hline$T_{a t m}$ & $\begin{array}{l}\text { atmospheric tem- } \\
\text { perature }\end{array}$ & $298.15 \mathrm{~K}$ \\
\hline$\eta_{c p}$ & $\begin{array}{l}\text { compressor effi- } \\
\text { ciency }\end{array}$ & $80 \%$ \\
\hline$\gamma$ & $\begin{array}{l}\text { ratio of specific } \\
\text { heats of air }\end{array}$ & 1.4 \\
\hline$R_{a}$ & air gas constant & $286.9 \mathrm{~J} /(\mathrm{kg} . \mathrm{K})$ \\
\hline$V_{s m}$ & $\begin{array}{l}\text { supply manifold } \\
\text { volume }\end{array}$ & $0.02 \mathrm{~m}^{3}$ \\
\hline$W_{c p}$ & $\begin{array}{l}\text { compressor outlet } \\
\text { mass flow rate }\end{array}$ & $0.1 \mathrm{~kg} / \mathrm{s}$ \\
\hline$k_{\text {sm,out }}$ & $\begin{array}{l}\text { manifold outlet ori- } \\
\text { fice }\end{array}$ & $0.3629 \times 10^{-5}$ \\
\hline$T_{s m}$ & $\begin{array}{l}\text { supply manifold } \\
\text { temperature }\end{array}$ & $300 \mathrm{~K}$ \\
\hline$R_{\mathrm{O}_{2}}$ & $\begin{array}{l}\text { oxygen gas con- } \\
\text { stant }\end{array}$ & $259.8 \mathrm{~J} /(\mathrm{kg} . \mathrm{K})$ \\
\hline$T_{s t}$ & stack temperature & $350 \mathrm{~K}$ \\
\hline$V_{c a}$ & cathode volume & $0.01 \mathrm{~m}^{3}$ \\
\hline$V_{r m}$ & $\begin{array}{l}\text { return manifold } \\
\text { volume }\end{array}$ & $0.005 \mathrm{~m}^{3}$ \\
\hline$T_{r m}$ & $\begin{array}{l}\text { return manifold } \\
\text { temperature }\end{array}$ & $300 \mathrm{~K}$ \\
\hline$p_{a t m}$ & $\begin{array}{l}\text { atmospheric pres- } \\
\text { sure }\end{array}$ & $101325 \mathrm{~Pa}$ \\
\hline$k_{c a, \text { out }}$ & $\begin{array}{l}\text { cathode outlet ori- } \\
\text { fice constant }\end{array}$ & $0.2177 \times 10^{-5}$ \\
\hline$M_{H_{2}}$ & $\begin{array}{ll}\text { hydrogen molar } \\
\text { mass }\end{array}$ & $2.016 \times 10^{-3} \mathrm{~kg} / \mathrm{mol}$ \\
\hline$M_{\mathrm{O}_{2}}$ & oxygen molar mass & $32 \times 10^{-3} \mathrm{~kg} / \mathrm{mol}$ \\
\hline$n$ & $\begin{array}{l}\text { cell number in fuel } \\
\text { cell stack }\end{array}$ & 381 \\
\hline$F$ & Faraday constant & 96485 Coulombs \\
\hline$K_{1}$ & proportional gain & 2.1 \\
\hline$K_{2}$ & $\begin{array}{l}\text { nominal pressure } \\
\text { drop coefficient }\end{array}$ & 0.94 \\
\hline$R_{H_{2}}$ & $\begin{array}{l}\text { hydrogen gas con- } \\
\text { stant }\end{array}$ & $4124.3 \mathrm{~J} /(\mathrm{kg} . \mathrm{K})$ \\
\hline$V_{a n}$ & anode volume & $0.005 \mathrm{~m}^{3}$ \\
\hline
\end{tabular}

[18] J.X. Chen and B. Zhou, Journal of Power Sources vol.177, (2008) pp.83-95.

[19] M.A. Rubio, A. Urquia and S. Dormido, Journal of Power Sources vol.171, (2007) pp.670-677.

[20] J. Stumper, M. Lohr and S. Hamada, Journal of Power Sources vol.143, (2005) pp.150-157.

[21] A. Ingimundarson, A.G. Stefanopoulou and D.A. McKay, IEEE TRANSACTIONS ON CONTROL SYSTEMS TECHNOLOGY vol.16, No.5, (2008) pp.1004-1012.

[22] W.L. Yang, K.Y. Lee, S.T. Junker and H. GhezelAyagh,Power and Energy Society General Meeting - Conversion and Delivery of Electrical Energy in the 21st Century, (2008) pp.1-8

[23] L.A M.Riascosa, M G. Simoesb and P E. Miyagic, Journal of Power Sources, Vol. 165, Issue 1, (2007) pp.267-278

[24] A. Hernandez, D. Hissel and R. Outbib, IEEE ISIE, July 9-12, (2006), Montreal, Quebec, Canada.

[25] A. Forrai, H. Funato, Y. Yanagita and Y. Kato, IEEE TRANSACTIONS ON ENERGY CONVERSION, Vol.20, No.3, (2005) pp.668-675.

[26] S. De Lira, V. Puig and J. Quevedo, 7th IFAC Symposium on Fault Detection, Supervision and Safety of Technical Processes, Barcelona, 30 June-3 July, (2009), Spain.

[27] Q. Yang, A. Aitouche and B.O. Bouamama, 7th IFAC Symposium on Fault Detection, Supervision and Safety of Technical Processes, Barcelona, 30 June-3 July, (2009), Spain.

[28] A. Rosich, F. Nejjari, and R. Sarrate, 7th IFAC Symposium on Fault Detection, Supervision and Safety of Technical Processes, Barcelona, 30 June-3 July, (2009), Spain.

[29] Q. Yang, A. Aitouche and B.O. Bouamama, 18th Mediterranean Conference on Control and Automation, 23-25 June, (2010), Morocco.

[30] M. L. Leuschen, I. D. Walker, and J. R. Cavallaro, IEEE TRANSACTIONS ON CONTROL SYSTEMS TECHNOLOGY, Vol.13, No.3, (2005) pp.452-458.

[31] K. Bouibed, A. Aitouche and M. Bayart, International Conference on Mechatronics and Automation, IEEE, 9-12 August, (2009), China.

[32] Q. Yang, A. Aitouche and B.O. Bouamama, 7th Workshop on Advanced Control and Diagnosis, November, (2009), Poland.

[33] C. Spiegel, PEM Fuel Cell Modeling and Simulation Using Matlab (Academic Press, USA 2008) pp.45.

[34] J.T. Pukrushpan, A.G. Stefanopoulou and H. Peng, Control of Fuel Cell Power Systems Principles, Modeling, Analysis and Feedback Design (Springer, USA 2004) Chap.2-3.

[34] W. Jiang, J. Khan and R.A. Dougal, Journal of Power Sources vol.158, (2006) pp.1333-1343.

[35] J.J. Gertler, Fault Detection and Diagnosis in Engineering Systems (Marcel Dekker New York 1998).

[36] P.M. Frank, Automatica, Vol.26, No.3, (1990) pp.459474.

[37] M.A. Djeziri, A. Aitouche and B.O. Bouamama, Proceedings of the 46th IEEE Conference on Decision and Control, New Orleans, USA, 12-14 Dec. (2007), pp.2578-2583.

[38] D. Theilliol, H. Noura and J.C. Ponsart, ISA Transactions vol.41, (2002) pp.365-382.

[39] T. Escobet, D. Feroldi, S. de Liraa, V. Puiga, J. Quevedoa, J. Rierab and M. Serrab, Journal of Power Sources vol.192, (2009) pp.216-223.

[40] A. Aitouche,B Ould Bouamama, International Journal of Automation and Control vol.4,No.3, (2010) pp.298-316. 
12 Aitouche et al: Fault Detection and Isolation of PEM Fuel Cell System based on Nonlinear Analytical Redundancy

[41] Q. Yan, H. Toghiani and H. Causeya, Journal of Power Sources Vol.161, (2006) pp.492-502.

[42] P E. Miyagi, L A M. Riascos, Control Engineering Practice vol.14,(2006) pp.397-408. 